\section{Lupus eritematoso cutáneo canino: algunas consideraciones acerca de la cercanía humana con los animales}

\section{Cutaneous lupus erythematosus in a dog: reflections on human-animal evolutionary connections}

\section{Sr. Editor:}

Deseamos presentar algunas reflexiones que surgieron a propósito de un caso clínico (Figura 1) visto en la práctica de una de las autoras. Nos llama la atención cómo se comparten los mecanismos que dan posibilidad a la vida. Esto se afirma en el hecho que somos seres bilaterales que crecen organizados por un conjunto de operaciones genéticas determinadas ${ }^{1}$. El ancestro común más primitivo compartido por todos los animales bilaterales, llamado Urbilateria, debe haber sido una criatura compleja que poseía, hace 525 millones de años (la explosión Cámbrica), las rutas genéticas que determinan gran parte de la organización espacial animal. Los estudios genéticos han demostrado que los genes Hox que controlan el desarrollo del eje antero-posterior en la mosca Drosophila y en las ranas Xenopus, al igual que la red genética Chordin-BMP (eje dorso-ventral), se encuentran también en vertebrados e invertebrados ${ }^{1}$. El descubrimiento de redes genéticas comunes que controlan el desarrollo embrionario y la habilidad de examinar registros genómicos fósiles ha revolucionado la teoría de la evolución de Darwin ${ }^{1}$.

Del mismo modo, existe una historia fascinante escrita en la década de 1990 que demuestra cómo el mecanismo de apoptosis se encuentra altamente conservado entre nematodos y mamífe$\operatorname{ros}^{2}$. Esta historia comienza con el artículo seminal de Vaux et al. en 1992, donde demostraron que la proteína humana bcl-2 podía bloquear la apoptosis en C. elegans de forma similar a como lo hacía ced-9. Esta fue la primera pista que sugirió que existía alguna ruta biológica en común. Dos años después, Hengartner et al. determinaron que la secuencia de la proteína ced-9 era $23 \%$ idéntica a la bcl-2 y, por lo tanto, eran homólogas. De modo paralelo, Miura et al. demostraron que la enzima convertidora de IL- $1 \beta$ humana era una proteína homóloga a ced-3, y por lo tanto, existían caspasas comunes en ambos procesos de muerte celular.

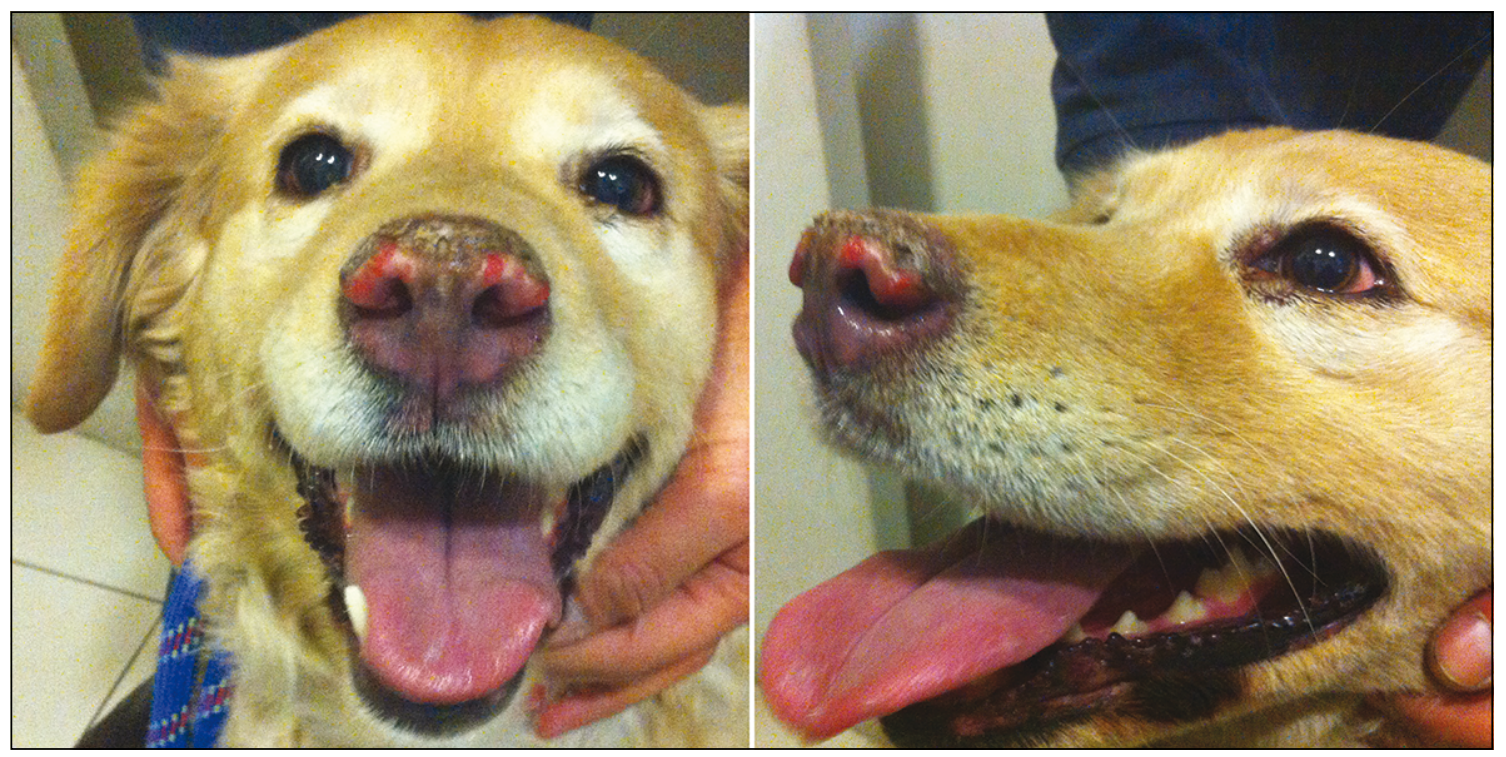

Figura 1. Lupus Eritematoso Cutáneo Canino en un Labrador Retriever. Paciente hembra de 6 años llega a consulta por presentar lesiones eritemoescamosas en plano nasal, pliegues epicánticos e hipopigmentación en zona periocular de tres semanas de evolución, que se agravan en días soleados. Se indicó cefalexina para descartar pioderma mucocutáneo. Al control a los 10 días sólo se evidenció una leve mejoría en el grado de eritema. Propietario rechazó biopsia de piel; anticuerpos antinucleares (-). Se realizó diagnóstico de LE cutáneo en base a respuesta positiva a tratamiento con prednisolona $1 \mathrm{mg} / \mathrm{kg}$ cada $24 \mathrm{~h}$ por 20 días, vitamina E 400 UI cada 12 h, omega 3 y 6 en alimento y uso de fotoprotección en zona nasal de forma permanente. 
Estas homologías también aparecen en el campo inmunológico. Los animales que dieron origen a los miembros vertebrados del phylum Chordata no poseían un sistema inmune adaptativo. La habilidad de recombinar segmentos genéticos y sintetizar proteínas únicas codificadas por nuevos patrones, fue adquirida 430 millones atrás en los primeros peces con mandíbula, gracias a la transferencia horizontal de transposasas de procariontes ${ }^{3}$. Así, el nacimiento de los vertebrados y su sistema neurológico se condice con la aparición de la producción de anticuerpos ${ }^{3}$. La idea de que la aparición de un sistema inmune adaptativo está asociada al desarrollo de la cresta neural, se refuerza aún más por el descubrimiento reciente de que algunas inmunoglobulinas facilitan el correcto desarrollo de los axones neuronales en C. elegans ${ }^{3}$.

Si es que existen semejanzas en los mecanismos biológicos durante la filogenia, es lógico que aparezcan procesos patológicos con manifestaciones clínicas en común entre especies. El estudio de los animales como modelos espontáneos de enfermedad es importante porque permite su mejor comprensión. En este sentido, la investigación comparada ha tomado dos rumbos: ha permitido preguntarse hasta qué punto las homologías genéticas determinan y restringen los resultados del proceso patológico, y cuáles son los efectos del ambiente que compartimos en común.

El lupus eritematoso (LE) es una enfermedad autoinmune. Sus manifestaciones clínicas van desde una forma cutánea indolora crónica hasta la muerte por compromiso multisistémico. Se piensa que su patogenia está relacionada con la pérdida de tolerancia debida a la presentación de autoantígenos nucleares disponibles en los cuerpos apoptóticos que normalmente son inaccesibles, a la vez que existen defectos en el clearance de estos cuerpos, y la activación anormal de células dendríticas que deberían conservar la tolerancia autóloga. El origen del material nuclear no es claro, pero en las lesiones cutáneas se piensa que el daño inducido por radiación ultravioleta permite la expresión de antígenos nucleares en los queratinocitos, junto con la expresión de diversas quemoquinas (proteínas del patrón interferón-1, ficolina 3, HMGBC 1) $)^{4}$. Gran parte del conocimiento acerca de la patogenia del LE proviene de estudios en roedores. Además de estar presente en humanos, el LE ha sido reconocido en perros, gatos, caballos, y se han reportados casos de "LESlike" en serpientes e iguanas 5 .

El lupus cutáneo canino es una enfermedad que se presenta con hipomelanosis, eritema, descamación y pérdida erosiva de la arquitectura normal del plano nasal. Existe un debate acerca de si el LE discoide corresponde al lupus cutáneo canino, debido a la similitud histopatológica ${ }^{6}$. Interesantemente, en los Pointer alemanes de pelo corto, existe una forma de LE cutáneo hereditario, asociada a una sustitución $\mathrm{G} \rightarrow$ A en la posición $54,866,704$ del intrón 3 del gen DPF2 en los perros afectados ${ }^{6}$. DPF2 es un gen que juega un rol importante en la apoptosis de las células mieloides y la renovación celular, por lo que podría estar involucrado en el LE cutáneo. El genoma del perro tiene una gran homología con el genoma humano. Un ejemplo de esto es que tiene $75 \%$ de genes ortólogos (18.473), la misma proporción entre los ratones y humanos ${ }^{7}$. El que existan razas claramente definidas es un experimento natural que tiene la ventaja de reducir la heterogeneidad de los loci, de modo similar al que ocurre en poblaciones aisladas geográficamente ${ }^{7}$. Esto permite estudiar enfermedades complejas, ya que un número restringido de genes o alelos resultan predominantes en la raza, como ocurre con la mutación 999 del 5 BRCA2 en las mujeres con cáncer de mama de Islandia o el LE cutáneo en los Pointers alemanes de pelo corto ${ }^{6,7}$.

Respecto a los efectos del ambiente sobre la etiología del LE, existe alguna evidencia epidemiológica de que podría existir algún factor transmisible. En un estudio de casos-controles se observó que la frecuencia de LES canino fue significativamente mayor en el grupo cuyo dueño era un paciente lúpico (3/59 perros, $5,08 \%)$ versus los que no (6/650 perros, $0,92 \%)$. Es decir, los perros expuestos a tener un dueño con LES tuvieron un riesgo relativo de padecer LES 20 a 100 veces mayor $^{8}$. Si se trata de un factor ambiental o un factor zoonótico, es aún una pregunta no resuelta.

Cristóbal Lecaros-Cornejo ${ }^{1, a}$, Camila Lecaros-Cornejo ${ }^{2, b}$, Sandra Díaz ${ }^{3, b}$

${ }^{1}$ Universidad de Antofagasta, Antofagasta, Chile.

${ }^{2}$ Universidad Austral de Chile, Valdivia, Chile. ${ }^{3}$ Departament of Veterinary Clinical Sciences, The Ohio State University, Ohio, United States. ${ }^{a}$ Interno de Medicina VII año. ${ }^{b}$ Médico Veterinaria. 


\section{Referencias}

1. De Robertis EM. Evo-devo: variations on ancestral themes. Cell 2008; 5; 132 (2): 185-95.

2. Conradt B. Comparing the molecular mechanisms of apoptosis in C. elegans and mammals. Lecture 4 in Programed Cell Death. A Course Offered By LudwigMaximilians-Universität München (LMU), an online learning initiative of LMU through Coursera. [Internet]. 2014. Available from: http://www.coursera.org

3. Bayne CJ. Origins and Evolutionary Relationships Between the Innate and Adaptive Arms of Immune Systems. Integr Comp Biol 2003; 43 (2): 293-9.

4. Kuhn A, Bijl M. Pathogenesis of cutaneous lupus erythematosus. Lupus 2008; 17 (5): 389-93.

5. Day MJ. Chapter 25-Systemic Lupus Erythematosus in Domestic Animals. In: Lahita RG, editor. Systemic Lupus Erythematosus (Fifth Edition) [Internet]. San Diego: Academic Press; 2011 [cited 2014 Sep 28]. p. 437-51.
Available from: http://www.sciencedirect.com/science/ article/pii/B9780123749949100257

6. Wang P, Zangerl B, Werner P, Mauldin EA, Casal ML. Familial cutaneous lupus erythematosus (CLE) in the German shorthaired pointer maps to CFA18, a canine orthologue to human CLE. Immunogenetics 2011; 63 (4): 197-207.

7. Ostrander EA. Both Ends of the Leash-The Human Links to Good Dogs with Bad Genes. N Engl J Med 2012; 367 (7): 636-46.

8. Chiou SH, Lan JL, Lin SL, Chen DY, Tsai NY, Kuan CY, et al. Pet dogs owned by lupus patients are at a higher risk of developing lupus. Lupus 2004; 13 (6): 442-9.

Conflictos de intereses: ninguno por declarar.

Correspondencia a:

Cristóbal Lecaros

clecarosc@gmail.com 